\title{
A CROSS-SECTIONAL STUDY ON THE PREVALENCE OF SELF-MEDICATION PRACTICES AND ITS ASSOCIATED FACTORS AMONG HOUSEWIVES IN RURAL AREAS OF ERNAKULAM DISTRICT
}

\author{
Kesley Elsa Kuriachan ${ }^{1}$,Greshma Susan George², Juhy Cherian³, Shilpa Mary Cheriyan', Lipsy Paul ${ }^{5}$
}

${ }^{1}$ M.B.B.S, Malankara Orthodox Syrian Church Medical College, Kolencherry.

2M.B.B.S, Malankara Orthodox Syrian Church Medical College, Kolencherry.

${ }^{3}$ M.B.B.S, Malankara Orthodox Syrian Church Medical College, Kolencherry.

${ }_{4}^{4}$ M.B.B.S, Malankara Orthodox Syrian Church Medical College, Kolencherry.

${ }_{5}^{5}$ Assistant Professor, Department of Community Medicine, Malankara Orthodox Syrian Church Medical College, Kolencherry.

\begin{abstract}
BACKGROUND

Self-medication can be defined as obtaining and consuming drugs without the advice of a physician. There is a lot of public and professional concern about the irrational use of drugs in Self Medication. Even if self-medication helps in reducing the burden on the health care system to a certain extent, it can lead to severe problems like antimicrobial resistance and addictions. This study will provide useful insight on the reasons for which patients resort to this practice and might help the policy makers and regulatory authorities to streamline the process of drug regulations and safety issues of over-the-counter drugs. This study also focuses on the attitude of people, who follow the practice of self-medication. Self-medication in modern pharmaceuticals seems to be a field in which information is scarce and to the best of our knowledge there is limited research conducted to reveal the extent of this problem in our community.
\end{abstract}

\section{OBJECTIVE}

To find out the prevalence of self-medication among housewives and to study the associated factors in rural areas of Ernakulum district.

\section{METHODOLOGY}

The rural areas selected for the study was the field areas of MOSC Medical College, Kolencherry; 163 subjects were studied (With $\mathrm{P}=71 \%$ from a study conducted on self-medication practices in coastal regions of South India.1). Cluster sampling was used to select subjects and data was collected using pretested interviewer administered questionnaire from those who signed the informed written consent. Data was entered using EPI INFO software and analysis was done using appropriate statistical tools. (Prevalence, probabilities, confidence limits were calculated).

\section{RESULTS AND CONCLUSIONS}

The prevalence of self-medication among housewives was $57.67 \%$ and included analgesics (81.9\%), antacids (31.91\%) and antibiotics were only used by $4.26 \%$.

\section{KEYWORDS}

Self-Medication, Self-Care, Housewives, Rural Areas, Previous Prescription.

HOW TO CITE THIS ARTICLE: Kuriachan KE, George GS, Cherian J, et al. A cross-sectional study on the prevalence of selfmedication practices and its associated factors among housewives in rural areas of Ernakulam district. J. Evolution Med. Dent. Sci. 2016;5(46):2909-2913, DOI: 10.14260/jemds/2016/678

\section{INTRODUCTION}

William Osler once quoted that "A desire to take medicine is perhaps the great feature, which distinguishes man from animals." This desire, however, may play havoc when a person starts taking medicines on their own (i.e. selfmedicating), forgetting that all drugs are toxic and their justifiable use in therapy is based on a calculable risk. ${ }^{2}$ Selfmedication can be defined as obtaining and consuming drugs without the advice of a physician. ${ }^{3}$ It is the selection and use of medicines. ${ }^{2}$ by individuals to treat self-recognized illnesses or symptoms.

Financial or Other, Competing Interest: None.

Submission 07-03-2016, Peer Review 01-05-2016,

Acceptance 24-05-2016, Published 09-06-2016.

Corresponding Author:

Dr. Kesley Elsa Kuriachan,

Cherattumoolayil- $H$,

Mamala P. O.,

Ernakulam-682305,

Kerala.

E-mail: koolkes15@gmail.com

DOI: 10.14260/jemds/2016/678
There is a lot of public and professional concern about the irrational use of drugs in Self Medication. In developing countries like India, easy availability of a wide range of drugs coupled with inadequate health services result in increased proportions of drugs used as Self Medication compared to prescribed drugs. Although, Over-The-Counter (OTC) drugs are meant for Self Medication and are of proved efficacy and safety, their improper use due to lack of knowledge of their side effects and interactions could have serious implications, especially in extremes of ages (Children and old age) and special physiological conditions like pregnancy and lactation.

There is always a risk of interaction between active ingredients of hidden preparations of OTC drugs and prescription medicines as well as increased risk of worsening of existing disease pathology. ${ }^{3}$ Self-care is a broad concept encompassing hygiene (General and personal), nutrition (Type and quality of food eaten), lifestyle (Sporting activities, leisure, etc.), environmental factors (living conditions, social habits, etc.), socioeconomic factors (Income level, cultural beliefs, etc.) and self-medication. Self-medication is very common and a number of reasons could be enumerated for it. ${ }^{4}$ increase in chronic diseases with its incidence increasing 
from $30-80 \%$ in the past 40 years, urge to self-care, feeling sympathy towards family members in sickness, lack of available health services, poverty, ignorance, misbeliefs, extensive advertisements and use of drugs from informal sectors such as open markets.

It has many potential benefits including person having an active role in his or her own health care, self-reliance in preventing or relieving minor symptoms or conditions and education opportunities on specific health issues (i.e. stop smoking aids and products to treat heartburn), saving scarce medical resources from being wasted on minor conditions, reducing absenteeism from work due to minor symptoms and also reducing the pressure on medical services where health care personnel are insufficient. It has potential risks including incorrect self-diagnosis, failure to seek appropriate medical advice promptly, incorrect choice of therapy, failure to recognize special pharmacological risks, rare but severe adverse effects, failure to recognize that the same active substance is already being taken under a different name, incorrect route of administration, inadequate or excessive dosage, excessively prolonged use and so on. ${ }^{5,6,7}$

Self-medication is an alarming concept. People have less knowledge regarding risks associated with their selfmedication. We are on the edge of sword whether to promote self-medication or not. 8 Self-medication in modern pharmaceuticals seems to be a field in which information is scarce and to the best of our knowledge there is no research conducted to reveal the extent of this problem in our community. Hence, we would like to expand knowledge and awareness regarding the same.

\section{METHODOLOGY}

We used cross-sectional study as our study design. Study setting was Field Areas of Department of Community Medicine, Malankara Orthodox Syrian Church Medical College, Kolencherry. Study period was from 10-8-2015 to 10-10-2015. Our study subjects were housewives in the field areas of Malankara Orthodox Syrian Church Medical College, Kolencherry, who were willing to take part in the study. Study was conducted among the houses coming under the six subcentres of Community Medicine Department of MOSC Medical College, Kolencherry. It included these areasKunnakurudy, Kandanadu, Nechoor, Kunnackal, Vazhappilly and Vettickal. We included all housewives who were physically present in the houses in our field areas during the data collection time and excluded all disabled women who were dependent on other family members for living. (Eg: Differently abled, blind), those who were reluctant to sign the consent and unmarried women.

Our sample size was 163 (by formula, 4PQ/L2, P=71\% from a study conducted on self-medication practices in coastal regions of South India. ${ }^{1}$ ). $Q=100-P, L=20 \%$ of $P$, total number of clusters $=6$, sample from each cluster $=163 / 6=\sim 27$ ). Cluster sampling was done $\{$ Rural areas selected for the project were the field areas of MOSC Medical College, Kolencherry. This was conducted by considering each field area as an individual cluster and hence a total of six clusters. One cross junction in each field area was selected and first house on the left side of the road was selected randomly (using Simple Random Sampling) and continued on the same side till cluster sample was achieved. When a road came to an end, we continued with the houses on the right side of the road\}. Data collection was done by using pretested interviewer administered questionnaire. For analysis, data was entered using EPI INFO software and analysis was done using appropriate statistical tools (Prevalence, probabilities, confidence limits were calculated). Institutional Ethics Committee approval was obtained. (IEC Protocol number: MOSC/IEC/117/2015).

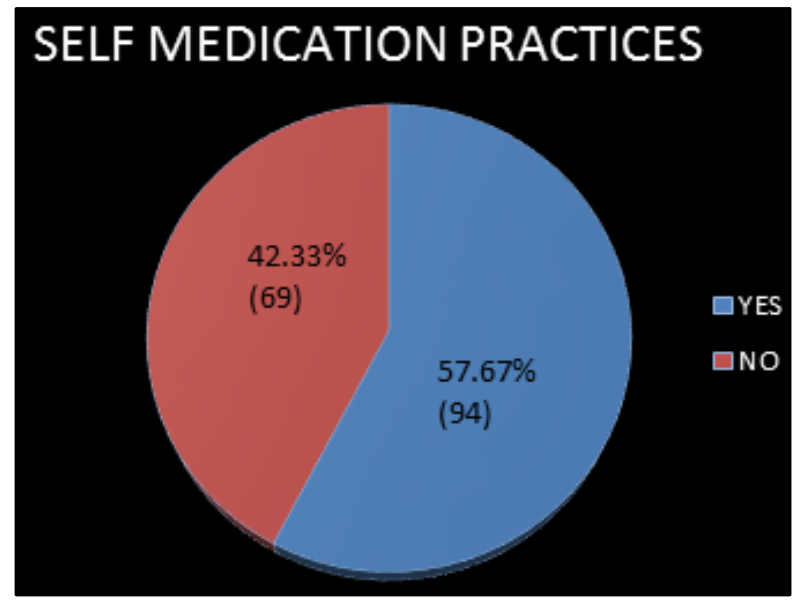

Fig. 1: Self-Medication Practices among Housewives ( $N=163)$

$57.67 \%$ (Confidence limits- $49.70 \%$ to $65.36 \%$ ) of the study population practiced self-medication.

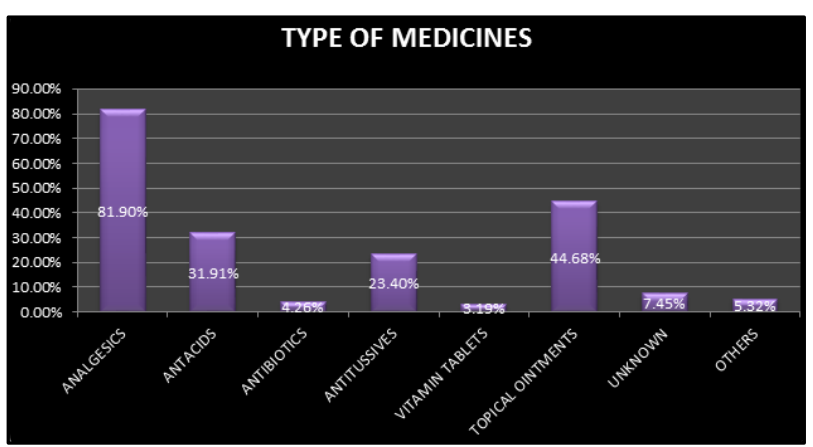

Fig. 2: Types of Medicines used in Self-Medication

Analgesics (81.9\%), antacids (31.91\%) and topical ointments $(44.68 \%)$ were the most commonly used medicines in Self Medication.

Multiple responses were allowed by study subjects.

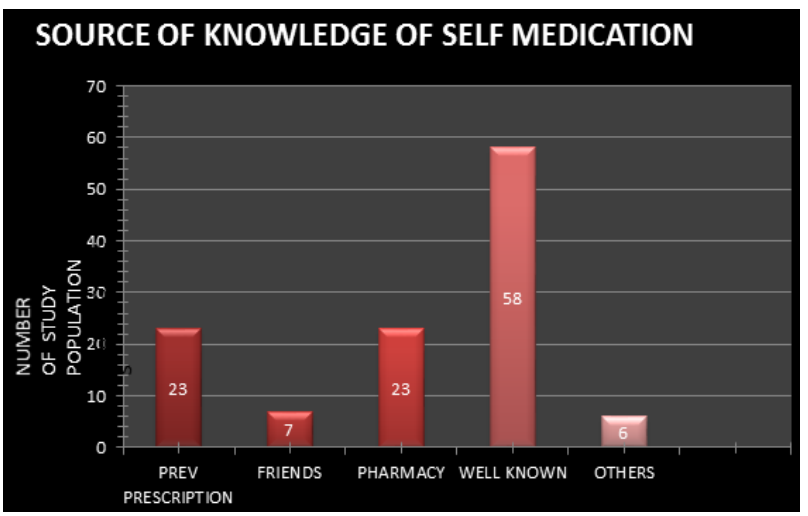

Fig. 3: Source of Knowledge for Practising Self-Medication

Practices adopted which were well known to the society and pharmacies were also found to be a common source. 


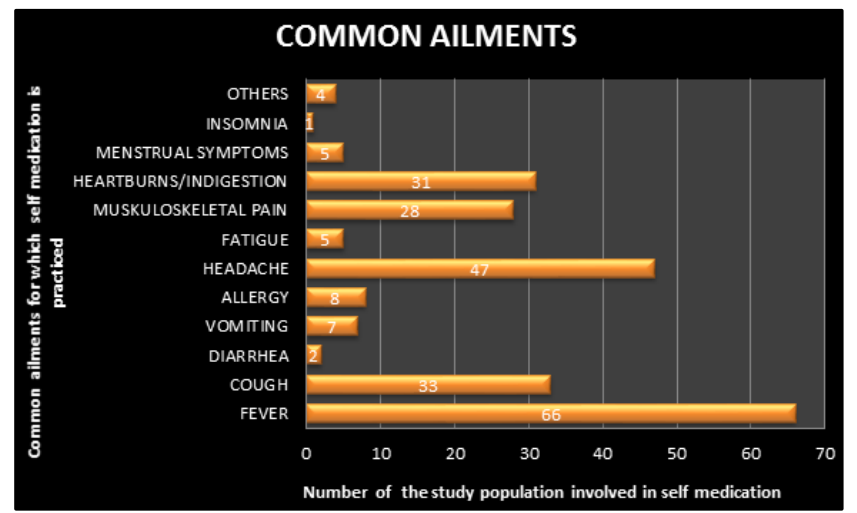

Fig. 4: Common Ailments for which Self-Medication was Practiced

Fever, headache and heartburns were the most common ailments.

Self-medication was predominant in the age group 40-50 years. There is no significant statistical association between age and self-medication.

\begin{tabular}{|c|c|c|c|}
\hline & \multicolumn{2}{|c|}{ Self-Medication } & \\
\hline Age (In years) & No & Yes & Total \\
\hline $20-30$ & $7(10.14)^{*}$ & $13(13.83)$ & $20(12.26)$ \\
\hline $31-40$ & $8(11.59)$ & $15(15.96)$ & $23(14.11)$ \\
\hline $41-50$ & $16(23.19)$ & $28(29.79)$ & $44(26.99)$ \\
\hline $51-60$ & $16(23.19)$ & $20(21.28)$ & $36(22.09)$ \\
\hline $61-70$ & $8(11.59)$ & $8(8.51)$ & $16(9.82)$ \\
\hline$>70$ & $14(20.2)$ & $10(10.6)$ & $24(14.72)$ \\
\hline Total & $69(100)$ & $94(100)$ & $163(100)$ \\
\hline \multicolumn{4}{|c|}{ Table 1: Association between Age \& } \\
Self-Medication Practices \\
\hline
\end{tabular}

*Figures in parenthesis are percentages.

Probability, $\mathrm{p}=0.4866$.

It was observed that self-medication was practiced the most among those with high school education and minimum among Graduates and illiterates.

There is no significant statistical association between selfmedication and education.

\begin{tabular}{|c|c|c|c|}
\hline & \multicolumn{2}{|c|}{ Self-Medication } & \\
\hline $\begin{array}{c}\text { Educational } \\
\text { Qualification }\end{array}$ & No & Yes & Total \\
\hline Illiterate & $8(11.59) *$ & $8(8.51)$ & $16(9.82)$ \\
\hline Primary School & $7(10.14)$ & $9(9.57)$ & $16(9.82)$ \\
\hline Middle School & $15(21.74)$ & $11(11.70)$ & $26(15.95)$ \\
\hline High School & $20(28.99)$ & $30(31.91)$ & $50(30.67)$ \\
\hline Intermediate & $9(13.04)$ & $20(21.28)$ & $29(17.79)$ \\
\hline Graduates & $10(14.49)$ & $16(17.02)$ & $26(15.95)$ \\
\hline Total & $\mathbf{6 9 ( 1 0 0 )}$ & $\mathbf{9 4 ( 1 0 0 )}$ & $\mathbf{1 6 3 ( 1 0 0 )}$ \\
\hline Table 2: Association between Self-Medication and \\
Education Qualification \\
\hline
\end{tabular}

*Figures in parenthesis are percentages.

Probability, $\mathrm{p}=0.3765$.

$83 \%$ sought professional advice after self-medication after minimum of 3-4 days up to a maximum of 1-2 weeks of self-medication, whereas $17.02 \%$ did not seek any professional advice at all.

\begin{tabular}{|c|c|c|}
\hline Seek Professional Advice & Frequency & Percentage \\
\hline No & 16 & 17.02 \\
\hline Yes & 78 & 82.98 \\
\hline Total & $\mathbf{9 4}$ & $\mathbf{1 0 0 . 0 0}$ \\
\hline \multicolumn{2}{|c|}{ Table 3: Tendency to Seek Professional } \\
Advice after Self-Medication \\
\hline
\end{tabular}

\begin{tabular}{|c|c|c|}
\hline Awareness of Leaflet & Frequency & Percentage \\
\hline No & 45 & 47.87 \\
\hline Yes & 49 & 52.13 \\
\hline Total & 94 & 100.00 \\
\hline \multicolumn{3}{|c|}{ Table 4: Awareness of the Existence of Drug Leaflets } \\
\hline
\end{tabular}

$52 \%$ were aware of the information pamphlets, which come with the drugs.

\begin{tabular}{|c|c|c|}
\hline Read the Leaflet & Frequency & Percentage \\
\hline No & 16 & 32.65 \\
\hline Yes & 33 & 67.35 \\
\hline Total & $\mathbf{4 9}$ & $\mathbf{1 0 0 . 0 0}$ \\
\hline \multicolumn{2}{|c|}{ Table 5: Percentage who are Aware } \\
and Read the Leaflets (N=49)
\end{tabular}

$67 \%$ who were aware had a habit of reading the drug information pamphlet.

\begin{tabular}{|c|c|c|}
\hline $\begin{array}{c}\text { Self-Medication } \\
\text { During Pregnancy }\end{array}$ & Frequency & Percentage \\
\hline No & 86 & 91.49 \\
\hline Yes & 8 & 8.51 \\
\hline Total & $\mathbf{9 4}$ & $\mathbf{1 0 0 . 0 0}$ \\
\hline \multicolumn{2}{|c|}{ Table 6: Adoption of Self-Medication in Pregnancy } \\
\hline
\end{tabular}

$8.5 \%$ used self-medication during pregnancy.

\begin{tabular}{|c|c|c|}
\hline $\begin{array}{c}\text { Suggest Self-Medication } \\
\text { to Others }\end{array}$ & Frequency & Percentage \\
\hline No & 65 & 69.15 \\
\hline Yes & 29 & 30.85 \\
\hline Total & $\mathbf{9 4}$ & $\mathbf{1 0 0 . 0 0}$ \\
\hline \multicolumn{2}{|c|}{ Table 7: Promotion of Self-Medication } \\
\hline
\end{tabular}

$31 \%$ gave suggestions to others regarding selfmedication.

\begin{tabular}{|c|c|c|}
\hline Justification & Frequency & Percent \\
\hline Depends on Illness & 45 & 47.87 \\
\hline No & 23 & 24.47 \\
\hline Yes & 26 & 27.66 \\
\hline Total & 94 & 100 \\
\hline
\end{tabular}

Majority (47.87) of the people who practice selfmedication justify the same depending on the illness.

During the analysis, we also found that $98 \%$ of the study population practiced home remedies. We also noticed that $37 \%$ were on regular medications, but none of them stopped their regular medications during self-medication.

\section{DISCUSSION}

In our study population, $57.67 \%$ (CI-49.7 to $65.36 \%$ ) adopted to self-medication practices, out of which $30 \%$ belonged to the age group 40 to 50 years. Study of self-medication used in 
the coastal regions of South India reported a prevalence of $71 \%$ and the age group being $26-45$ years. ${ }^{1}$ Study of selfmedication done in Urban Puducherry reported a prevalence of $11.9 \% .{ }^{9}$ and that done in Haryana is $73 \%{ }^{4}$

Housewives with high school (32\%) and intermediate (21\%) education showed maximum tendency to selfmedicate and graduates (17.02\%) and illiterate $(8.51 \%)$ showed lesser tendency. In contrast to our study results that done in Haryana showed a greater prevalence among graduates $(53 \%)$ and postgraduates $(21 \%){ }^{4}$

The most common system of medicine used for selfmedication was Allopathy (94\%) and the rest practiced Ayurveda and Homeopathy. Analgesics (81.9\%) being the most common medicine used for self-medication followed by topical ointments (44.68\%), antacids (31.91\%), antitussives $(23.4 \%)$ and others (5.32\%). Antibiotics were only used by $4.26 \%$ and unknown medicines by $7.45 \%$. In comparison to the study of self-medication done in Urban Puducherry, which showed the use of Analgesics (27.2\%) and Antibiotics $(9.5 \%)$ to be predominant. ${ }^{9}$ Similar pattern was observed in the study conducted in Haryana [Analgesics (81\%), Antacids (44\%), Antibiotics (33\%) and Topical (34\%)]. ${ }^{4}$

The knowledge of self-medication was from the wellknown self-medication practices in the community (61.7\%), which was not observed in other studies. Other sources included - from previous prescriptions (24.47\%), pharmacist (24.47\%), friends (7.45\%) and others $(6.38 \%)$ which was found to be similar to the Study in coastal regions of South India [Pharmacist (57.3\%) and previous prescriptions (21.5\%)]. ${ }^{1}$ Urban Puducherry [Pharmacists (31.8\%)]. ${ }^{9}$ and Haryana [Previous prescriptions (49\%) and advertisements $(26 \%) .^{4}$

Self-medication was mainly practiced for quick relief $(50 \%)$ and also because the study population felt that illness was too trivial (48.94\%) for consultation. Other reasons included financial restraints (14.89\%), lack of time $(11.7 \%)$, distance from the health centre (8.5\%), chronic musculoskeletal illness (8.5\%) and others (8.5\%). A similar trend was seen in the study conducted in the coastal regions of South India. ${ }^{1}$

The most common ailments for which self-medication was practiced were for fever (66\%), headache (50\%), cough (35\%), heartburns/indigestion (32.98\%) and musculoskeletal pain (29.79\%), allergy (8.5\%), nausea and vomiting $(7.45 \%)$, fatigue $(5.32 \%)$, menstrual symptoms (5.32\%), diarrhoea (2\%), insomnia (1\%) and others $(4.26 \%)$. Similarly, the study conducted in the coastal regions of South India reported fever (36\%), headache (35\%), cough, cold and sore throat (20\%) to be the most common ailments for which self-medication was practiced. ${ }^{1}$ This was also observed in Urban Puducherry where fever, headache and abdominal pain were the most common ones. ${ }^{9}$

Out of those who self-medicate, only $33 \%$ of population had knowledge regarding the dose and duration of drugs used; however, only $15 \%$ had experienced the misfortune of misdiagnosis. In a study conducted in Haryana, $41 \%$ had knowledge regarding the drugs that they use for self medication. 4

$65 \%$ had a habit of storing medications at home, mostly in cupboards and tabletops, and such was the case in $97 \%$ of housewives of Haryana. ${ }^{4}$
$82 \%$ had a good habit of checking the expiry date before self-medication and similar was the pattern seen in the study conducted in Haryana (80\%). ${ }^{4}$

$60.64 \%$ and $53.19 \%$ did not have awareness regarding the side effects and the relationship of the drugs with food intake used in self-medication respectively. In the study conducted in Haryana, 49\% had knowledge regarding side effects of drugs. 4

$30.85 \%$ recommended self-medication practices to other population and $15.95 \%$ justified self-medication; $66.6 \%$ of the study subjects justified the use of self-medication in a study conducted in Urban Puducherry. ${ }^{9}$ In contrast, $71 \%$ did not justify the use of self-medication in Haryana. ${ }^{4}$

\section{CONCLUSION}

We have come to the conclusion that in our study population, $57.67 \%$ adopted to self-medication practices. Well educated and illiterates showed least tendency, whereas those with high school education showed maximum tendency to selfmedicate, again proving that little knowledge is dangerous. As expected, analgesics were the most common medicines used for self-medication followed by antacids and topical ointments. It was pleasant to learn that antibiotics were only used by $4.26 \%$, but all the same concerned that medicines taken were unknown to $7.45 \%$. The knowledge of selfmedication was mainly from the well-known self-medication practices in the community and also from previous prescriptions and pharmacist. Self-medication was mainly practiced for quick relief and for illnesses too trivial for consultation. It was alarming to know that a minor proportion of pregnant women practiced self-medication. More than half of the study group was unaware regarding the side effects. A quarter of them were of the opinion that selfmedication is justifiable depending on the illness.

\section{LIMITATIONS}

1. Our sample size was limited and did not represent the extent of the problem, which also represents the shortage of time to interview a larger population.

2. The accuracy/reliability of the responses from housewives in terms of unawareness of drugs used/tendency to hide drugs used as self medication.

3. Our questionnaire did not adapt in circumstances where homeopathy/Ayurveda was used as selfmedication due to our limited knowledge of the side effects/dosing in homeopathic/Ayurvedic medications.

\section{SUGGESTIONS}

1. People must be made aware of the fact that one can develop allergy and side effects to even common medicines like paracetamol.

2. We have found that majority believe self-medication is wrong which is a misconception, aim should be to promote the ideology of responsible self-medication and awareness on when to seek professional help should be imbibed into them.

3. Government should make policies and see to it that drugs are not repeatedly purchased using previous prescriptions by working hand in hand with drug dispensers and all health care professionals keeping in mind the health of the people and the harmful effects of the unauthorized use of medicines. 
4. As we found that many do not have knowledge regarding proper techniques of drug storage, importance of the same must be emphasized in the society.

\section{REFERENCES}

1. Balamurugan E, Ganesh K. Prevalence and pattern of self-medication used in coastal regions of South India. British Journal of Medical Practitioners BJMP 2011;4(3):a428.

2. Phalke V, Phalke D, Durgawale P. Self-medication practices in rural Maharashtra. Indian J Community Med 2006;31(1):34-5.

3. Montastruc JL, Bagheri H, Geraud T, et al. Pharmacovigilance of self-medication. Therapie 1997;52(2):105-10.

4. Bennadi D. Self-medication: a current challenge. J Basic Clin Pharma 2014;5(1):19-23.
5. Guidelines for the regulatory assessment of medicinal products for use in self-medication. Apps.who.int. 2016. Available from:

http://apps.who.int/medicinedocs/en/d/Js2218e/.

6. The role of the pharmacist in the health care system. Apps. who. int. Available from: http://apps.who.int/medicinedocs/en/d/Jh2995e/.

7. Shankar PR, Partha P, Shenoy N. Self-medication and non-doctor prescription practices in Pokhara valley, Western Nepal: a questionnaire based study. BMC Fam Pract 2002;3:17.

8. Kaushal J, Gupta MC, Jindal P, et al. Self-medication patterns and drug use behaviour in housewives belonging to the middle income group in a city in northern India. Indian J Community Med 2012;37(1):16-9.

9. Selvaraj K, Kumar SG, Ramalingam A. Prevalence of selfmedication practices and its associated factors in Urban Puducherry, India. Perspect Clin Res 2014;5(1):32-6. 